\title{
Prevalence of HIV among Adolescent Children in Abuja, the Federal Capital Territory, Abuja Nigeria
}

\author{
S. B. Mohammed, Y. Ya'aba, M. Njoku, M. C. Abarike, K. S. Izebe, M. N. Ezeunala, \\ M. Usoroh, E. Asawa, K. T. Olatunji, A. R. Abdulmumin, P. Oladosu, O. P. Adigwe \\ National Institute for Pharmaceutical Research and Development (NIPRD), Abuja, Nigeria \\ Email: mshehubusu@yahoo.com
}

How to cite this paper: Mohammed, S.B., Ya'aba, Y., Njoku, M., Abarike, M.C., Izebe, K.S., Ezeunala, M.N., Usoroh, M., Asawa, E., Olatunji, K.T., Abdulmumin, A.R., Oladosu, P. and Adigwe, O.P. (2019) Prevalence of HIV among Adolescent Children in Abuja, the Federal Capital Territory, Abuja Nigeria. Open Journal of Epidemiology, 9, 321-328.

https://doi.org/10.4236/ojepi.2019.94023

Received: October 9, 2019

Accepted: November 25, 2019

Published: November 28, 2019

Copyright () 2019 by author(s) and Scientific Research Publishing Inc. This work is licensed under the Creative Commons Attribution International License (CC BY 4.0).

http://creativecommons.org/licenses/by/4.0/ c) (i) Open Access

\begin{abstract}
Adolescents in Africa have low HIV testing rates. Determining the HIV prevalence among this group is very important because adolescents living with HIV (ALHIV) have worse health outcome than other populations of people living with HIV. This study aimed at determining the prevalence of HIV among children of adolescents age (10 - 18 years) that come for HIV testing in virology laboratory of National Institute for Pharmaceutical Research and Development, Abuja from January 2013 to December 2018. The result was expressed in percentage and disaggregated by sex. Out of 533 adolescents tested over 6 years, $252(51.9 \%)$ females and 234 (48.1\%) were males. A total of $69(14.1 \%)$ of them were tested HIV positive which $42(8.6 \%)$ were females and 27 (5.5\%) were males. The result of this study indicates that there is epidemics of HIV among adolescents living in Federal Capital Territory Abuja. It is also evident that females are more vulnerable to HIV infection than the males. There is therefore need for urgent standard and comprehensive procedure for adolescents living with HIV transitioning from paediatric to adult care. This also calls for intensive enlightment on HIV education especially in our basic and post basic schools in Abuja.
\end{abstract}

\section{Keywords}

Adolescent, Abuja, Prevalence, Paediatric, HIV

\section{Introduction}

Adolescence is a transitional phase between childhood and adulthood characterized by unique and rapid physiological, cognitive and emotional changes with evolving capacities during the transition. Rapid physical and hormonal devel- 
opment during adolescence is characterized by a desire for self-discovery, an emerging sense of autonomy, separation from parents and urge for independence, recognition and acceptance often lead to risky behaviors. The defined age range of adolescence varies, but is generally accepted to begin with puberty and end in the transition to adulthood [1]. These changes from childhood to adulthood can be both rewarding and challenging for all adolescents as they are predisposed to high risk behaviours to HIV AIDS [2] [3] [4]. For those adolescents living with HIV (ALHIV), this transition is exacerbated by a chronic, stigmatized and sexually transmissible disease [5]. The youth are much more prone to HIV infection as well as other sexually transmitted infections as a result of a lack of correct health information, engagement in risky behaviors, economic exploitation, regional and national conflicts and a lack of access to adequate reproductive health services [6] [7].

World Health Organization reported that in 2015, there were about 1.2 billion adolescents aged 10 - 19 years, accounting for $16 \%$ of the world's population [8]. They are unique and sometimes neglected group in the planning of healthcare services. This is the case in many parts of sub-Saharan Africa, where more than eight out of ten of the world's HIV-infected adolescents live [1]. Worldwide, over $40 \%$ of new infections are among young people 15 - 25 and nearly $50 \%$ of the 35.3 million people living with HIV acquired infection before the age of 25 years through sexual transmission [9] [10]. It was reported that $80 \%$ of AIDS cases worldwide are within the age bracket of 15 and 24 years old and three-quarter of these individuals live in sub-Saharan Africa [11]. Although significant progress has been made in understanding the pathogenic mechanisms, transmission, clinical features, complications of HIV/AIDS and in the area of reducing the number of new HIV cases and the number of HIV related deaths, as more people are adopting safer sexual behaviours there is still no cure and the disease remains a public health challenge with large numbers of new infections [2] [12]. Every day 5000 young people in the world become infected with HIV, which translates into almost 2 million new infections per year [13]. It is worthy to note that with increasing survival of vertically HIV-infected children and ongoing new horizontal HIV infections, the population of adolescents (age 10 - 19 years) living with HIV is increasing [8]. This increase, brings novel challenges to health systems and HIV programs required to respond to the unique needs of this changing population, with current HIV services generally geared towards adult or younger paediatric populations [3]. This therefore, calls for a new concern to focus attention on HIV infection among adolescents. The data showed that even if there are data on HIV test on general population, they are not disaggregated into adolescents to expose the trend of HIV infection among this group. Data also show that adolescents (15 - 19 years) old engage in high risk sexuality. It was found out that $56.4 \%$ and $39.6 \%$ of sexually boys and girls respectively, had unprotected sex with non-marital sex partners. The proportion of adolescents who engage in this high risk sexual behaviour was higher than what was observed in 
other age groups [9]. Other high risk behaviours such as transactional sex, multiple sex partnership, age mixing of sexual partners are on the increase among adolescents in Nigeria [14]. The trends of HIV infection among youth and particularly remain understudied despite these facts and where reports exist, HIV prevalence data among this group has not been highlighted. The aim of our study is to determine the prevalence of HIV among adolescents in Abuja.

\section{Material and Methods}

\subsection{Materials}

All reagents used were of analytical grade. The HIV testing kits were Determine ${ }^{\oplus}$ HIV-1/2 Test Cards (Inverness Medical, Japan), Unigold ${ }^{\mathrm{Tm}}$ kit (Trinity Biotech, Ireland) and Stat Pak ${ }^{\oplus}$ HIV-1/2 (Chembio Diagnostic Systems Inc. USA).

\subsection{Study Population}

The study was carried out amongst 486 adolescents between the ages of 10 to 18 years that came for HIV testing voluntarily or by referral to Virology unit in the Department of Microbiology and Biotechnology, National Institute for Pharmaceutical Research and Development Idu Abuja from January 2012 to December 2017.

\subsection{Ethical Consideration}

Ethical clearance was sought from the Institutional Review Board of the National Institute for Pharmaceutical Research and Development Abuja. The participants were sufficiently counseled and informed consent obtained with the assurance that all information would be treated with confidentiality. Those who are above 16 years of age, signed the consent forms themselves while the guardians of those below 16 years signed on their behalf.

\subsection{Sample Collection and Sample Analysis}

Blood sample was collected by finger-pricking. The finger-tip was sterilized with cotton wool soaked with $70 \%$ alcohol by swabbing. A sterile lancet was used for pricking the finger and the blood that came out first was wiped off using dry tissue paper. The pricked finger was pressed from the base towards the finger-tip to allow good flow of blood. The blood sample was collected into two capillary tubes for testing. The testing for the presence of HIV antibodies was carried out using Determine ${ }^{\oplus}$ HIV-1/2 Test Cards (Inverness Medical, Japan), Unigold ${ }^{\mathrm{mix}}$ kit (Trinity Biotech, Ireland) and Stat Pak ${ }^{\oplus}$ HIV-1/2 (Chembio Diagnostic Systems Inc. USA) using serial algorithm.

Each sample was screened for the presence of HIV-1/2 antibodies using Determine test kits. Those samples that were reactive to HIV1/2 antibodies were then confirmed using Unigold test kits. The discordant results were resolved using Stat Pak test kits. The results were disaggregated by age and sex while the prevalence was expressed in percent. 


\section{Results}

\subsection{Distribution of HIV among Adolescents According to Sex and Year of Testing}

A total of 532 adolescents present for HIV testing between January 2013 to December 2018. 289 (54.3\%) were females while 243 (45.7\%) were males. A total of $68(12.8 \%)$ of them were tested HIV positive which 42 (7.89\%) were females and $26(4.89 \%)$ were males. The result indicated that more female adolescents were tested than the males and more females were tested HIV positive (Table $1)$.

\subsection{Distribution of HIV Infection among Adolescents According to Age Group and Year of Testing}

On disaggregation by age bracket none of the clients was positive within the age bracket of 10 - 12 in 2014 and 2018, only one person was positive in the years 2013 and 2015, while 4 and 2 clients were positive in the years 2016 and 2017 respectively. The result also showed that the higher adolescents, the higher the prevalence of HIV infection. The older adolescents are more infcted in the years under study (Figure 1).

\section{Discussion}

It is estimated that $50 \%$ of HIV-infected adolescents live in just six countries and that 15 countries account for $75 \%$ of all HIV-infected adolescents globally with 13 countries in sub-Saharan Africa, one in Asia and one in South America [8].

The findings of this study indicated that more females turned out for voluntary testing than the males. The result also indicated that more female adolescents are HIV positive compare to their male counterparts. This may be as a result of differences in sexual risk behavioural pattern among the adolescents based on their HIV prevalence. This is in consonants with the report of Folayan et al., [9] where more females were found to be HIV positive compared to male

Table 1. Prevalence of HIV among adolescents according to sex and year of testing.

\begin{tabular}{ccccc}
\hline \multirow{2}{*}{ Years } & \multicolumn{3}{c}{ Sex } \\
\cline { 2 - 5 } & No. of Clients & $\begin{array}{c}\text { No. of positive } \\
\text { clients }\end{array}$ & No. of clients & $\begin{array}{c}\text { No. of positive } \\
\text { clients }\end{array}$ \\
\cline { 2 - 5 } & $59(11.09 \%)$ & $4(0.75 \%)$ & $68(12.8 \%)$ & $6(1.13 \%)$ \\
2013 & $52(9.77 \%)$ & $3(0.56 \%)$ & $39(7.33 \%)$ & $5(0.94 \%)$ \\
2014 & $46(8.64 \%)$ & $8(1.50 \%)$ & $57(10.7 \%)$ & $6(1.13 \%)$ \\
2016 & $37(6.95 \%)$ & $5(0.94 \%)$ & $58(10.9 \%)$ & $12(2.26 \%)$ \\
2017 & $33(6.20 \%)$ & $4(0.75 \%)$ & $36(6.77 \%)$ & $8(1.50 \%)$ \\
2018 & $16(3.00 \%)$ & $2(0.38 \%)$ & $31(5.83 \%)$ & $5(0.94 \%)$ \\
Total & $243(45.7 \%)$ & $26(4.89 \%)$ & $289(54.3 \%)$ & $42(7.89 \%)$ \\
\hline
\end{tabular}




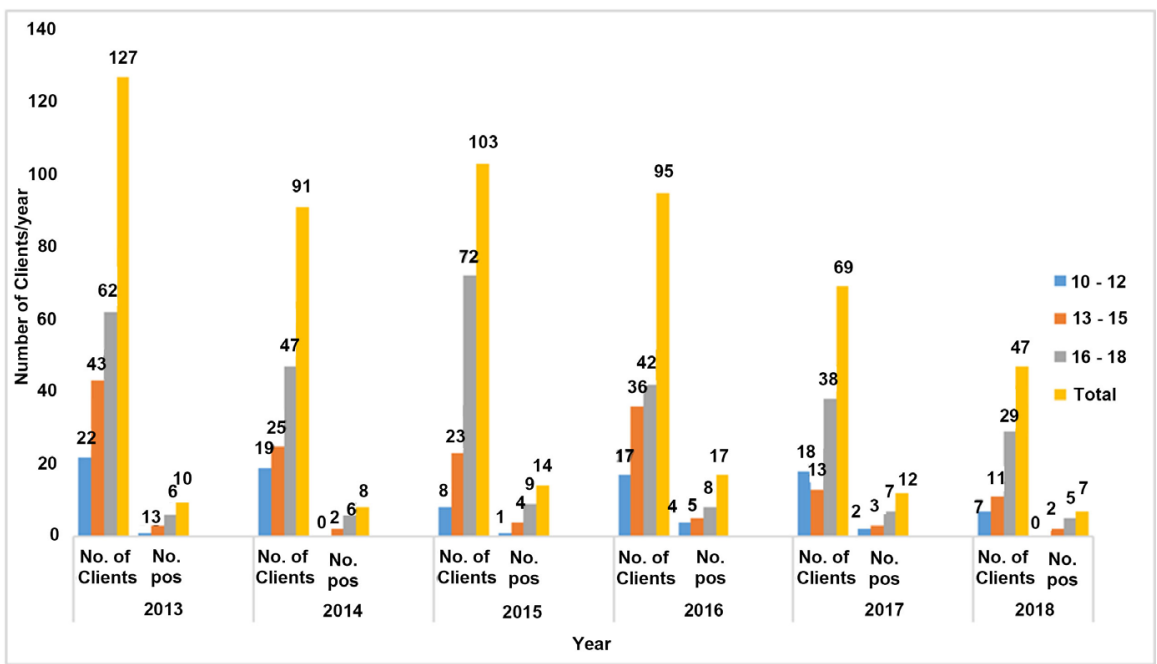

Figure 1. Prevalence of HIV among adolescents disaggregated by age group and year of testing.

adolescents in some selected states in Nigeria. This is also in accordance with the findings of Ijeoma, et al., [11] where prevalence of HIV was higher amongst the females $(4.32 \%)$ than males (2.92\%). It is also worthy to note that except for the year 2014, the prevalence of HIV was always higher among the female adolescents compare with their male counterparts.

The result of $12.8 \%$ prevalence of HIV among the adolescents is an indication of large number of adolescents living with HIV (ALHIV). This can be explained by the fact that the high perinatal transmission rate of HIV, put at $27.3 \%$ at the end of 2013 and reduced rate of infant mortality from HIV due to successful antiretroviral programmes increase the likelihood of the country to have a large population of adolescents living with HIV. This is also in agreement with the results of the study by [9]. Another important highlight of this study is that it is able to capture the people within the age group of 10 and 15 years of age. This will make the result of this contribution as an important tool for policy and programing.

Different risks and barriers experienced during the stages of younger (age 10 - 14 years) and older (age 15 - 19 years) adolescence have impacted on the HIV-related outcomes as well as on the risk for HIV acquisition. Younger adolescents are more often living at home, are in early stages of puberty and fewer have reached sexual debut compared with older adolescents [8]. The findings of this study showed that the prevalence of HIV increases with increase in age of adolescents. Those within the age bracket of $10-12$ years had $1.5 \%$ prevalence, those within the age bracket of 13 - 15 were $3.57 \%$ and 16 - 18 years was $7.7 \%$. During older adolescence, HIV acquisition risk becomes apparent with higher risk among older adolescents. The uptick in adolescent HIV prevalence with increase in age could be explained by adoption of risky sexual behaviour by older adolescents.

Age-disaggregated data and evidence of effective service delivery interventions to support adolescents are lacking. Even though it is estimated that HIV-related 
deaths among adolescents have tripled since 2000, that made HIV the second leading cause of mortality in this age group. Mark et al., [3] reiterated that all-cause mortality rates in the general adolescent population are lower than in other age groups, adolescents have been regarded as a healthy population not requiring much attention of healthcare services [15]. Therefore, it is evident that global HIV monitoring systems have not been paying attention to this vulnerable group until recently which has posed challenges to understanding the kinetics of HIV infection and pragmatic methods of its control. Consequently, national program that will be oriented towards monitoring the health and risk behaviours towards HIV is imperative for targeting AIDS free society. Health information systems have not been oriented towards monitoring adolescent health.

\section{Conclusion}

Programs which target at mitigating transmission of HIV among adolescents were generally not included in the country comprehensive HIV control programs. This probably may be as a result of the fact that staging and definition of adolescents is dependents on not only in individuals but also country dependent. The group is also neglected because the members of this group who are just coming out of the care of their parents mostly considered themselves as newly liberated individuals that don't care much of their health status and therefore are not captured properly on the intervention programs because of scarcity of situational data. However, this study and some few available survey conducted in some parts of the world has shown that prevalence of HIV is high among this group. There is need for concerted effort in developing policies and immediate outreach implementation. This is necessary to achieving AIDS free society as advocated.

\section{Limitations of the Study}

The study was only conducted among those youths that came for voluntary counselling and testing for HIV who are mostly on referral or those that may be having health challenges. There is no fund to conduct a wider survey among the general adolescent population that can truly determine the situation in this vulnerable population group.

\section{Acknowledgements}

We sincerely acknowledge the management of National Institute for Pharmaceutical Research and Development for giving us the opportunity to carry out this study. We also acknowledge the Presidential Emergency Program for AIDS Relief (PEPFAR) through the Institute for Human Virology Nigeria (IHVN) for supporting our facilities which has increased our output in HIV testing.

\section{Conflicts of Interest}

The authors declared no conflict of interest. 


\section{References}

[1] Adejumo, O.A., Malee, K.M., Ryscavage, K., Hunter, S.J. and Taiwo, B.O. (2015) Contemporary Issues on the Epidemiology and Antiretroviral Adherence of HIV-Infected Adolescents in Sub-Saharan Africa: A Narrative Review. Journal of the International AIDS Society, 18, Article ID: 20049. https://doi.org/10.7448/IAS.18.1.20049

[2] Shiferaw, Y., Alemu, A., Girma, A., Getahun, A., Kassa, A., et al. (2011) Assessment of Knowledge, Attitude and Risk Behaviour towards HIV/AIDS and Other STIs among Property Students of Gondar Town, Northwest Ethiopia. BMC Research Notes, 4, 2-8. https://doi.org/10.1186/1756-0500-4-505

[3] Mark, D., Armstrong, A., Andrade, C., Penazzato, M., Hatane, L., Taing, L., Runciman, T. and Ferguson, J. (2017) HIV Treatment and Care Services for Adolescents: A Situational Analysis of 218 Facilities in 23 Sub-Saharan African Countries. Journal of the International AIDS Society, 20, 21591. https://doi.org/10.7448/IAS.20.4.21591

[4] World Health Organization (2014) Health for the World's Adolescents: A Second Chance in the Second Decade. Geneva.

http://apps.who.int/adolescent/second-decade/

[5] Sohn, A.H. and Hazra, R. (2013) The Changing Epidemiology of the Global Paediatric HIV Epidemic: Keeping Track of Perinatally HIV-Infected Adolescents. Journal of International AIDS Society, 16, 18555. https://doi.org/10.7448/IAS.16.1.18555

[6] Eaton, J.W., Garnett, G.P., Takavarasha, F.R., Mason, P.R., Robertson, L., et al. (2013) Increasing Adolescent HIV Prevalence in Eastern Zimbabwe: Evidence of Long-Term Survivors of Mother-to-Child Transmission. PLoS ONE, 8, e70447. https://doi.org/10.1371/journal.pone.0070447

[7] Chen, F.P. (2008) HIV/AIDS Prevent among Young People in East and South-East Asia in the Context of Reproductive and Sexual Health. Asia Pacific Population Journal, 23, 7-28. https://doi.org/10.18356/2f9cf12d-en

[8] Slogrove, A.L., Mahy, M., Armstrong, A. and Davies, M.-A. (2017) Living and Dying to be Counted: What We Know about the Epidemiology of the Global Adolescent HIV Epidemic. Journal of the International AIDS Society, 20, 21520. https://doi.org/10.7448/IAS.20.4.21520

[9] Folayan, M.O., Morolake, O.M., Brown, B. and Harrison, A. (2014) Differences in Sexual Behaviour and Sexual Practices of Adolescents in Nigeria Based on Sex and Self-Reported HIV Status. Reproductive Health. 11, 83. https://doi.org/10.1186/1742-4755-11-83

[10] Joint United Nations Program on HIV/AIDS (2013) At the Crossroads: Accelerating Youth Access to HIV/AIDS Interventions. http://www.un.org/esa/socdev/unyin/documents/aidsunfpa.pdf

[11] Ijeoma, E.N., Bartholomew, O.I. and Tochukwu, E.O. (2014) High HIV Sero-Prevalence among Students of Institutions of Higher Education in Southeast $\mathrm{Ni}$ geria. Asian Pacific Journal of Tropical Diseases, 4, 159-165. https://doi.org/10.1016/S2222-1808(14)60334-0

[12] Joint United Nations Programme on HIV/AIDS (UNAIDS) Global Report: UNAIDS Report on the Global AIDS Epidemic 2013. UNAIDS, Geneva, Switzerland. https://www.unaids.org/en/resources/documents/2013/20130923\%C2\%AC_UNAID S_Global_Report_2013

[13] UNAIDS (2015) Beginning of the End of the AIDS Epidemic. The Gap Report. 
http://www.unaids.org/sites/default/files/media_asset/UNAIDS_Gap_report_en.pdf

[14] Aboki, H., Folayan, M.O., Daniel, U. and Ogunlayi, M. (2014) Changes in HIV Sexual Risk Behaviour among Adolescents aged 15-19 Years over a Five-Year Period: Is the HIV Prevention Programme in Nigeria Yielding Results? African Journal of Reproductive Health, 18, 108-116.

[15] Global Burden of Disease Pediatrics Collaboration (2016) Global and National Burden of Diseases and Injuries among Children and Adolescents between 1990 and 2013: Findings from the Global Burden of Disease 2013 Study. JAMA Pediatrics, 170, 267-287. 